\title{
Heterocyclic Chemistry - Old Science or the Forefront of Chemistry?
}

Oliver Reiser* (1)

Institut für Organische Chemie, Universität Regensburg, Universitätsstraße 31, 93053 Regensburg, Germany oliver.reiser@chemie.uni-regensburg.de
Received: 14.08.2017

Accepted: 14.08.2017

Published online: 21.08 .2017

DOI: 10.1055/s-0036-1589511; Art ID: st-2017-b3000-c

Oliver Reiser studied chemistry at the Universities of Hamburg, Jerusalem and Los Angeles (UCLA) and earned his Ph.D. degree from the University of Hamburg (Prof. Armin de Meijere) in 1989. After postdoctoral stays at IBM Research Center (Dr. Robert D. Miller) and Harvard University (Prof. David A. Evans), he started his independent research in 1992 at the University of Göttingen. In 1996, he moved to the University of Stuttgart as an Associate Professor and in 1997, to the University of Regensburg as Professor of Chemistry. His research group specializes in catalysis starting from renewable resources such as furans and pyrroles toward fine chemicals, natural products and drugs. He is currently serving as President of the International Society of Heterocyclic Chemistry.

It is difficult to pinpoint the exact starting point of organic chemistry, but undoubtedly heterocycles belonged to the players of the first hour. Going back to the beginning of the $19^{\text {th }}$ century, a hallmark discovery can be placed to 1818-almost exactly 200 years ago-with the isolation of alloxan (Figure 1) from uric acid by Luigi Valentino Brugnatelli. Approximately 20 years later, Döbereiner discovered furfural while distilling ants to produce formic acid. The ant bodies probably contained some plant material which served as its source, and indeed, the production of furans from pentoses and hexoses has developed today into one of the most important processes for the utilization of renewable resources as fine chemicals or biofuels. In the following two centuries, a seemingly endless variety of heterocycles has been produced: approximately 25 million compounds are known to date, being ubiquitous in natural products, drugs and materials.

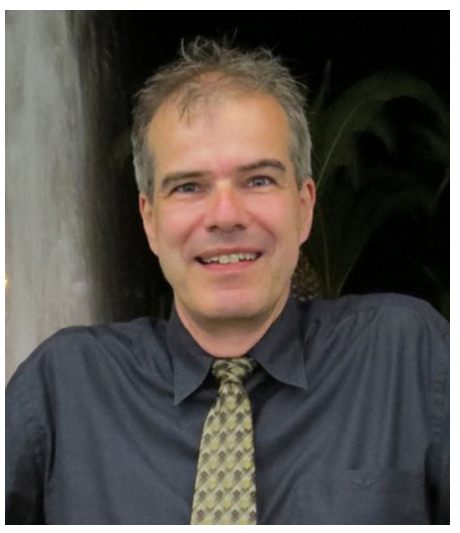
found in Nature or being applied in smart materials has greatly advanced the field of synthetic organic chemistry. Emerging technologies and methods such as flow chemistry, C-H-activation, organocatalysis and visible light photocatalysis often find early applications in conjunction with heterocyclic chemistry. Stereoselective synthesis and catalysis would not be possible without the aid of heterocyclic auxiliaries, directing groups or ligands. Arguably, heterocyclic chemistry is the major driving force for these developments. 
Synlett

This Cluster on heterocycles is a joint effort between Synlett and the International Society for Heterocyclic Chemistry (ISHC, http://www.ishc-web.org), which is celebrating its $50^{\text {th }}$ anniversary this year. The 15 articles and accounts reflect some of the exciting developments in heterocyclic chemistry that will be presented at ISHC 26, being held in Regensburg from September 3-8, 2017. Almost 70 plenary, invited and oral contributions along with 290 posters will impressively demonstrate the vibrant field of heterocyclic chemistry. I am especially excited that the ISHC 2017 awardees: Prof. Yasuyuki Kita (Ritsumeikan University, Japan), winner of the E. C. Taylor Senior Award, and Prof. Chris Vanderwal (UC Irvine, USA), winner of the A. R. Ka- tritzky Junior Award, have contributed their latest results in an account and an article. Renowned speakers of ISHC 25, which was held in 2015 in St. Barbara, USA, complement the contributions of the current speakers.

I would like to express my gratitude to Thieme, a longstanding supporter of the ISHC conference.

Prof. Dr. Oliver Reiser University of Regensburg

President ISHC 